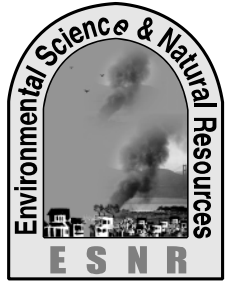

\title{
Analytical Study and Monitoring of Winter Events in Bangladesh Using Satellite Data
}

\author{
S. Begum*, M. A. Muhammad, S. Chakma and S. B. Shaha \\ Bangladesh Space Research and Remote Sensing Organization (SPARRSO) \\ *Corresponding author: bsuraiya89@yahoo.com
}

\begin{abstract}
In recent years Bangladesh has experienced numerous winter events during the winter. In January 2010, northern and southwest parts of the country experienced a rapid fall in temperature with cold winds and dense fog. In January 2011 the Meteorological Department recorded the temperature as 2 to 5 degrees Celsius lower than the normal average temperature (about $10^{\circ} \mathrm{C}$ ) during that time of the previous year'sresulting significant rise in respiratory illnesses, and in some cases deaths. Some prior arrangement should be made and preparatory measures should be taken by the respective departments, agencies to protect the affected people.Monitoring and prediction prior to the events is thus necessary. Satellite data are very useful for monitoring and analytical study of such natural events and their directional movement. SPARRSO monitors the formation, duration and movement of cold wave as one of its regular activities relating to disaster management, based on data received at its own ground station. In this paper,monitoring of winter events and their analytical study using satellite data will be discussed briefly.
\end{abstract}

Key words: Monitoring, Natural events, Rapid fall, Satellite, Tropical

\section{Introduction}

The months December, January and February form the winter season in Bangladesh. During this season, pressure over the country increases south to north as part of the Siberian high (Skamaruk et al., 2008). The air temperature drops down significantly and thus the atmosphere remains foggy, mostly the river bank areas (Houze, 1993).Fog is a water vapor, an invisible gas that forms when it's very, very humid. The water vapor condenses around the microscopic solid particles of dust (Orlanski, 1975; Smith, 1979).Cloudless conditions and descending motion of air compress the air and brings in the cold to the ground level (Malukar, 1949). Every year cold wave with fog flows from west and passes over Bangladesh in this season. For last few years the country had experienced some severe cold waves with fog that caused serious damage, distress and disruption for the people (http://reliefweb.int). Meteorological Department recorded the temperature as 2 to 5 degrees Celsius lower than the normal average temperature (about $10^{\circ} \mathrm{C}$ ) during that time of the previous years. A huge portion of the population of the country is living under poverty line not having adequate capacity to cope with extreme weather events such as severe cold waves. Unable to buy warm clothes, poor people are struggling to ward off cold bite at night (http://www.buet87). As the sun could not be seen throughout the day in many places and as chilly wind blew, poor people who do not have adequate warm clothes are suffering the bite of bitter chill as a mild to moderate cold wave (http://www.imdpune). Unable to buy warmclothes, poorpeopleare struggle in toward off cold bite at night.Low-income people living in chars and by rivers and roads and in slums try to keep themselves warm by making fire.The impact of cold waves is as notorious as other regular natural calamities of Bangladesh as far as the damage, distress and disruption as well as death toll is in concern. Elderly and children are most victims and tend to suffer from pneumonia, diarrhea, asthma and other cold related diseases due to cold waves (http://primenews). Hospitals in the affected districts have reported higher numbers of admissions with cold weather related illnesses like. So far the cold wave of January 2011 claimed 39 and December 2012 claimed 72 lives (http://reliefweb.int). Due to dense fog transport systems and ferry services are often cease to function causing sufferings to the people (http://www.buet87). The weather has also caused crop and other natural resource loss, which will have a longer-term negative impact on the economic situation for the poor communities in the worst affected areas (http://primenews). A natural event is termed as disaster when it adversely affects the whole environment, including human beings, their shelters, or the resources essential for their livelihoods (Lin, 1993). To sustain such calamities people at the affected areas need external support and aids from the government and other humanitarian agencies prior to the event. Though some of the humanitarian agencies have already started taking prior preparation, all other relevant organizations may need to put some more effort for proper action (http://primenews). Monitoring is important for this purpose. The space based data i.e., the satellite data are very useful in this regard. The objective of this study is to monitor the formation, duration and movement of such events as well as to find out the most affected areas.

\section{Materials and Methods}

SPARRSO at its ground station receive space based data from different Meteorological Satellites like FY-2D, MTSAT etc. These satellite data were 
mainly used to monitor winter events for this study. Space based data received from other satellites like TERRA/MODIS and NOAA-series satellites are very much helpful in this regard too.Data from daily weather report provided by BMD were also used in this study. The satellite data were processed using vimsat and gmsoft software for these purposes and enhanced for clear visualization to make easy for monitoring. Analysis of data provides an indication of the origin and aerial extent of the wave(SPARRSO Annual report, 2010, 2013).The satellite images acquired in the visible and infrared regions of the solar spectrum showed appreciable sensitivity to the presence, properties and spatial distribution of fog. The shape of the wave and its directional movement are very much visible on the satellite images (SPARRSO Newsletter, 2011).

\section{Monitoring}

During winter, seasonal high pressure area fills the area vacated by predecessor low-pressure. This became apparent as an area of higher atmospheric pressure slotted itself into position over the region (http://www.buet87). In a low pressure system, air has an ascending motion; it expands and rises into the atmosphere, cools, forms clouds and drops as fog (Houze, 1993). Cloudless conditions and descending motion of air compress the air and brings in the cold to the ground level (Lin, 1993).

In 2009, cold wave with fog appeared on Bangladesh at late and continued up to February, 2010. It passed over Bangladesh three times(Weather Bulletin). The durations of the cold waves were short (SPARRSO Annual report, 2010).

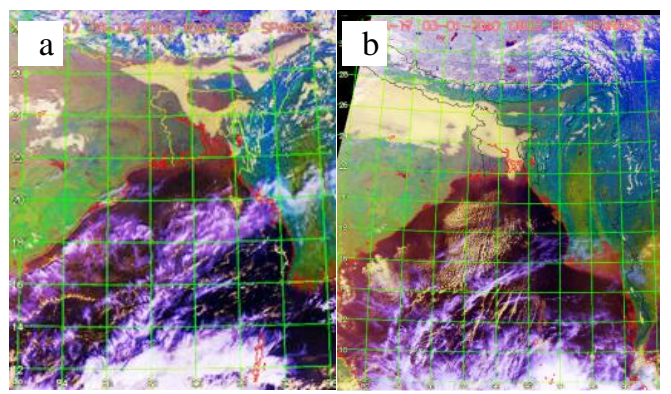

Fig.1. (a) Winter events spread over Bangladesh in a. December 2009; (b) January 2010. (Yellowish white in Satellite image)

The country experienced rapid fall in temperature and a severe cold wave on 1 January, 2010
(SPARRSO Annual report, 2010). In satellite data the shape of the fog and its directional movement with cold wave are clearly visible (Fig.1).

In 2012, cold wave with fog started from 08 December (SPARRSO Annual report, 2012). A cold wave struck the northern districts of the subHimalayan regions of Bangladesh, claiming more than 72 lives since mid-December (http://reliefweb). The cold wave has also caused crop and other natural resource losses, which results a longer term negative impact on the economic situation of the country. Two light to moderate cold wave/fog occurred in December, 2012.The wave propagated through the central part of the country (http://primenews). It then began to spread over towards north and northeastern direction (SPARRSO Newsletter, 2013). It ultimately extended over the whole country except greater district of Chittagong Hill-tracks (Fig.2) and continued up-to 28 January, 2013 (Weather Bulletin, 2013).
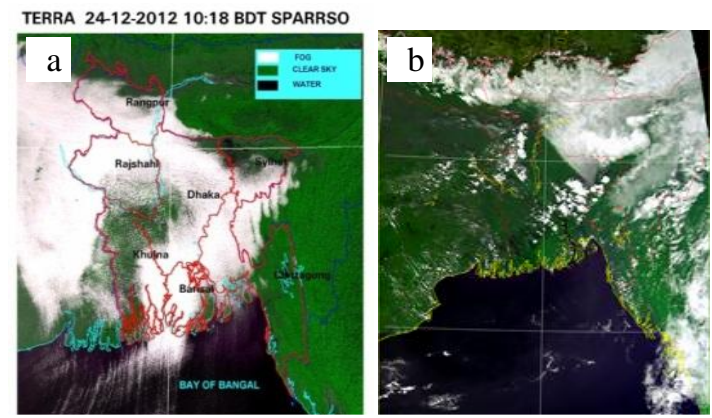

Fig. 2. (a) Winter events spread over Bangladesh, a. 24, December, 2012; (b). February, 2012 (shows white in TERRA-satellite image)

Winter events of the following years 2013- 2014 and2014-2015 were similarly monitored using satellite data (Fig. 3).

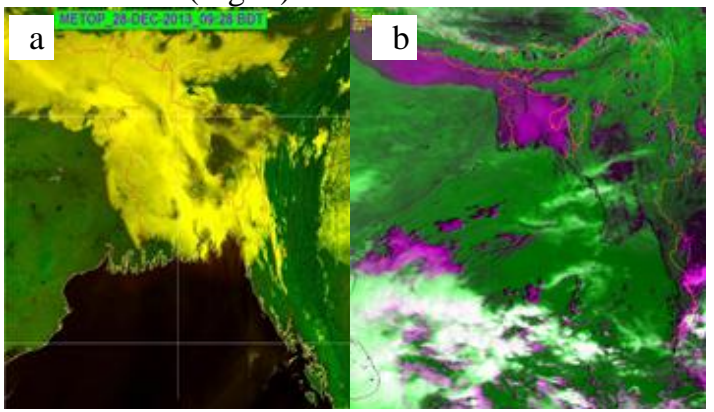

Fig. 3. (a) Winter events spread over Bangladesh, December, 2013 (showsyellow in TERRA-Satellite image; (b) December, 2014 magenta in MTSAT satellite image 


\section{Results and Discussion}

Two mild to moderate cold waves $\left(08^{\circ} \mathrm{C}-10^{\circ} \mathrm{C} /\right.$ $06^{\circ} \mathrm{C}-08^{\circ} \mathrm{C}$ ) were sweep across the northern, northeastern and central parts of the country during the month of December, one moderate to severe cold waves $\left(06^{\circ} \mathrm{C}-08^{\circ} \mathrm{C} / 04^{\circ} \mathrm{C}-06^{\circ} \mathrm{C}\right)$ passed over the northern, northeastern and central parts and one mild to moderate cold wave $\left(08^{\circ} \mathrm{C}-10^{\circ} \mathrm{C} /\right.$ $06^{\circ} \mathrm{C}-08^{\circ} \mathrm{C}$ )passed over the other parts of the country in January and one mild cold wave $\left(08^{\circ} \mathrm{C}\right.$ $10^{\circ} \mathrm{C} / 06^{\circ} \mathrm{C}-08^{\circ} \mathrm{C}$ ) were swiped across the northern and central parts of the country in the month of February(Weather Bulletin).It is found that, winter events usually occur at the end of December and beginning of January and ends at the middle of February; the northern part of the country is the mostly affected area.

\section{Conclusions}

As emergency relief is not effective after cold waves, prior preparation for emergency response is more essential for such disaster affected people.

\section{References}

Houze, R.A. 1993. Cloud dynamics.Academia, p.573.

Lin, Y.L. 1993. Orographic effect on airflow and meso-scale weather system over Taiwan.Ocean Atmosphere, 4:381-400

Malukar, S.L. 1949. Proc. Nat. Inst. Sci. India, 15:p. 161.

Orlanski, I. 1975. A rational subdivisions of scales for atmospheric process. Bull. Am. Met. Soc., 56:527-520.

Skamaruk, W.C.; Klemp, J.B.; Gill, D.O.; Baker, D.M. and Huang, X. 2008. A description of the advanced research WRF. Technical note., 3: p.475.

Smith, B. 1979.The influence of mountains on atmosphere.AdvancesOn Geophy., 21:87-130. 